\title{
Mobile-Assisted Language Learning in L2 Korean Using WeChat: A Case Study
}

https://doi.org/10.3991/ijim.v16i01.24007

\author{
Arum $\operatorname{Kim}^{(\mathbb{})}$ \\ Centre of Foreign Language and Culture, BNU-HKBU \\ United International College, Zhuhai, China \\ arumkimauic.edu.cn
}

\begin{abstract}
Learners studying Korean as a foreign language have a longstanding problem in language learning: less exposure to the target language and a lack of communicative learning opportunities. This study attempts to explore how these challenges can be solved by incorporating mobile technologies - especially WeChat - into Korean language learning. By examining the implementation of the WeChat Project's five components, this study reports on the advantages and disadvantages of using mobile technologies for students who learn an intermediate Korean language course at a liberal arts college in China. A total of 16 students participated in a one-semester study, and they were asked to complete an end-of-semester questionnaire and attend a follow-up interview. The questionnaire's results revealed that students generally welcomed the WeChat Project and that they positively perceived the usefulness of the five components of the WeChat Project. In the interviews, the students reported four major benefits of using WeChat in their Korean learning: increased learning time, an acquisition of linguistic knowledge, the Korean language community, and the convenience of using WeChat. The disadvantages and suggestions for improvements are discussed.
\end{abstract}

Keywords-Korean as a foreign language, Korean language learning, mobile-assisted language learning, WeChat

\section{$1 \quad$ Introduction}

As interest in Korean culture has increased worldwide, the number of Korean learners abroad has steadily increased, and China is no exception. The greatest difficulty for Chinese Korean learners is that they have less exposure to the Korean language, a lack of practice time, and little interaction.

Students who study Korean at higher education institutions in China are digital natives, belonging to the "i-generation" cohort. They have been exposed to various digital environments since their birth, are generally proficient at using digital devices and technologies, and enjoy social activities through social media platforms. As the use of digital devices and technologies has become embedded in students' lives, active discussions regarding how Korean can be learnt using these devices and technologies are required.

WeChat is the most widely used social media platform in China [1], [2]. It is an all-inone communication application that allows all users to text and call each other directly, as 
well as exchange photos, videos, and files for free. It allows users to conduct group chats via the "Chats" function, construct a community with friends by uploading text messages, pictures, or videos on their own "Moments," and receive push notifications on public platforms [3]. Because of the variety of capabilities, WeChat-based language learning has been discussed in several workshops and conferences. However, very few empirical studies have examined the effectiveness of implementing WeChat in teaching and learning Korean as a foreign language (KFL). To bridge this research gap and contribute to a better understanding of KFL, this study conducted empirical research to examine the effect of incorporating WeChat into KFL at a Chinese liberal arts university. This study aims to provide practical data for improving the Korean language learning environment abroad.

\section{State of the art}

\subsection{Mobile-assisted language learning}

With the continuous development of mobile technology and the popularization of mobile internet devices, mobile-assisted language learning (MALL) has become an irreversible trend and has attracted increasing attention from scholars. Currently, there is no consensus regarding the definition of mobile learning among scholars. However, mobile learning can be generally perceived as teaching and learning that uses mobile technologies and devices (e.g., smartphones, media players, and tablets) and that can help learners learn anytime, anywhere [4].

Despite some challenges (e.g., see [5], [6], and [7]), many researchers have reported the considerable advantages of MALL. Kukulska-Hulme [8] noted that MALL supports multimedia, collaborative listening, and speaking activities and allows learners to co-construct knowledge to solve problems and fill information gaps. Miangah and Nezarat [9] stated that mobile learning potentially allows the learning process to be personalized, spontaneous, informal, and ubiquitous. Lee [10] mentioned that students can access educational content, e-books, and textbooks through their mobile devices anytime and anywhere as long as they bring the mobile devices that they use for learning; this is MALL's greatest advantage for students [10].

Zaki and Yunus [11] mentioned that mobile learning comprises the features of mobility, ubiquity, wireless networking, interactivity, accessibility, and privacy and that these features have great potential for mobile learning in teaching academic writing in English as a second language.

Similarly, Burston [12] conducted a meta-analysis of MALL study's learning outcomes over the past two decades. His analysis revealed that 15 studies demonstrated the benefits of MALL applications by reporting positive learning results in the areas of reading, listening, and speaking.

\subsection{MALL studies among Korean language learners}

Although many scholars have studied MALL over the past decade, there is still a significant lack of MALL research in Korean language learning. Only recently have 
experimental studies been conducted on the learning effects of MALL using specific applications such as WeChat, Instagram, KaKao Talk, etc.

Kwon [13] indicated that the KFL education environment is different from that of "Korean as a second language (KSL)," and that the writing tasks tend to be skipped or assigned as homework - especially in a class with limited time. In response, she suggested a lesson plan for a Korean writing class that used Facebook as a teaching and learning platform for the writing lessons that could not be fully covered in a classroom. Based on the current study's end-of-semester questionnaire, the results indicated that students strongly agreed that MALL through Facebook helped them improve their writing skills and increase their opportunities for exposure to the Korean language.

Ahn and Shim [14] explored how Instagram could be used to supplement elementary-level Korean language courses in American public universities. They designed six different types of learning materials and uploaded them regularly on Instagram throughout the semester. After the semester was completed, a survey was conducted to determine students' satisfaction levels. From the 44 students' responses, the study found that Instagram 1) was more accessible to students than any other learning management system; that using it 2) was fun and students were willing to participate; that it 3 ) increased target language exposure and authentic language use; that using it 4) increased interactions between teachers, students, and other native speakers; and that it 5) helped students improve their listening and other language skills.

Han [15] explored how "KakaoTalk" could be implemented in a Korean language course in a university in Hong Kong. She reported that students welcomed the use of MALL and that it helped encourage communication among the students and teachers. Therefore, MALL could be a potential solution to the lack of exposure, practice, and interaction in language learning.

In a recent study, Kim [16] conducted a semester-long study that applied MALL through flipped learning in a Korean language classroom in China. The study demonstrated that this type of learning with MALL positively affected academic performance, especially communicative listening and speaking skills.

As can be observed in these studies, Korean language teachers and scholars have been conducting MALL studies of Korean language learning by incorporating mobile technology into their teaching and learning in Korean language classrooms. However, there have been no reported cases of WeChat being applied to actual classes in this field.

WeChat is the only application in China to have over one billion active users (Google search) and is available for free. Its operating system is simple, easy to update [17], and supports Android, iOS, Symbian, Windows Phone, and BlackBerry, which are the top five global smartphone operating systems and account for $99.4 \%$ of the market share [9].

Given these advantages, WeChat is highly likely to play an influential role in MALL, especially in China. Further research is needed to shed light on the use of WeChat in the future. To bridge this research gap, this study has conducted experiments to explore the availability of WeChat in Korean language learning with a case study. 


\section{Methodology}

\subsection{Participants}

This study was conducted on 17 Korean language learners at a liberal arts college in Guangdong Province, China.

As the university's second foreign language course consisted of a step-by-step learning series, students who took "Korean 3" successfully completed both "Korean 1" and "Korean 2." The average learning period varied from 12 to 63 months. However, because this study targeted current college students, the age group was concentrated on students aged $19-24$ years $(100 \%)$. The proportion of female participants was higher, with $16(94 \%)$ females and $1(6 \%)$ male.

\subsection{Description}

This study (hereafter referred to as the "WeChat Project") was incorporated into the syllabus of the KOR2003 course (i.e., Korean 3), and it accounted for $10 \%$ of the total course assessments. Just before the first class of 2020, an official WeChat group chat room was established for the "Korean 3" course. The first day of the class was dedicated to introducing the WeChat group chat and WeChat Project to students. At this time, the instructor confirmed that all students had their own WeChat accounts and that they could use WeChat's various functions.

Students were notified that WeChat would be used to support their Korean language learning in five ways. Students would use it to 1) share lecture video clips; 2) ask and answer questions; 3) perform simple writing tasks; 4) socialize; and 5) share information related to lectures. The first four components would be marked according to the video clips watched, tasks being fulfilled, comment quality, and participation and contribution to the class WeChat group. Details of the five components included the following:

- Share lecture video clips. The instructor pre-recorded what the students would learn in the next class and shared the video clips on WeChat. Students were required to watch the video clips in advance and attend the class, and the video clips were then used as a review after the class.

- Ask and answer questions. Each student was required to ask their classmates questions using the new expressions and vocabulary that they had learned in their previous lessons. It was highly recommended that they ask at least one question a week, as well as answer questions when they were asked.

- Perform simple writing tasks. At the end of every lesson, students completed a simple writing task using grammar and expressions that were covered in the lesson. They would post these tasks in the WeChat group chat and could share their thoughts after reading each other's writing tasks.

- Socialize. The instructor encouraged students to make the most of the WeChat group chat. Students could socialize and share their thoughts, opinions, and information. The most welcomed information was related to Korean language learning resources (e.g., video clips, website URLs, and interesting reading materials). 
- Share information related to lectures. This component was mainly conducted by the instructor; therefore, students' participation was not graded. It was based on guiding students using information about assignments, deadlines, and assessment methods during the semester as well as notifications about reviews and preparation for the next class.

Among the five components described above, the second and third components required the use of Korean. The fourth component recommended Korean but allowed English or Chinese, depending on the circumstances. The instructor first guided the fifth component in Korean, but then again in English when students were concerned that they did not fully understand Korean because of its complicated content. The sample data for the simple writing task are shown in Figure 1.

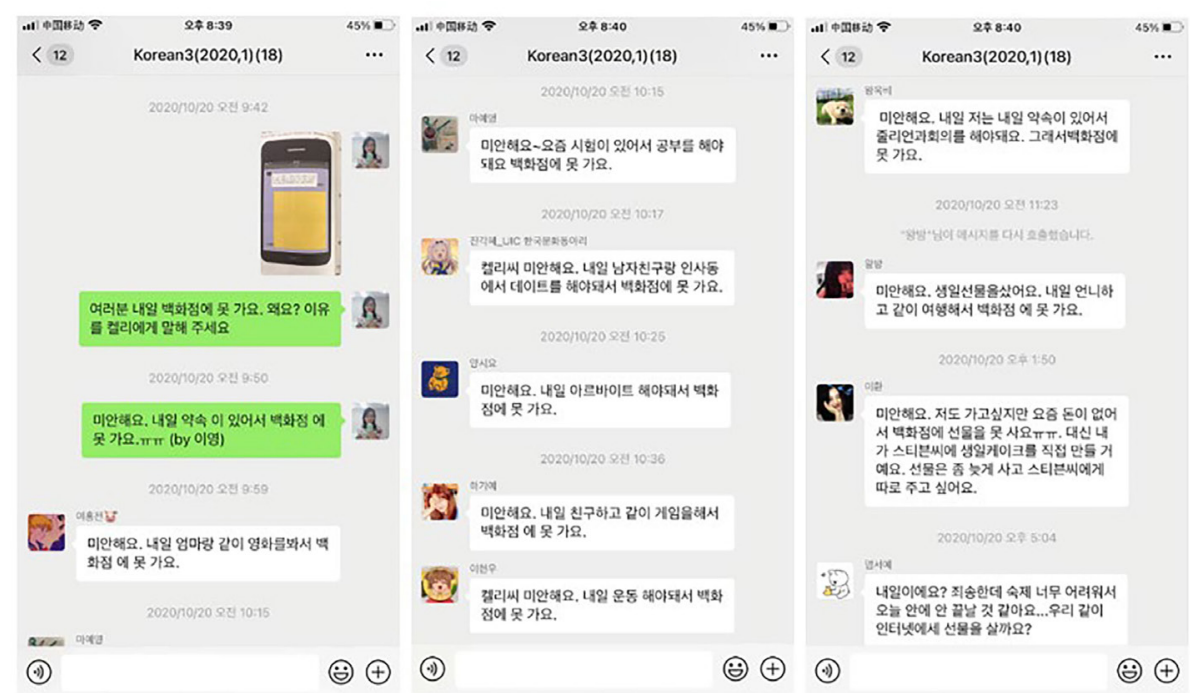

Fig. 1. Screenshot of simple writing task

\subsection{Tools}

This study applied a mixed-method design that involved a questionnaire and follow-up interviews.

On the last day of the semester, the participants were asked to complete a questionnaire that comprised four main parts: basic learner information, overall satisfaction with the WeChat Project, degree of usefulness in the five learning support components that were used in the WeChat Project, and willingness to use WeChat in future Korean learning. The questionnaire was designed to be graded on a 7-point Likert scale for each question, and it provided room for a simple reason for the rating. Of the 17 questionnaires returned, 16 were valid and were used for the data analysis. One questionnaire was excluded because there were several missed answers. Detailed items of the questionnaire are shown in Table 1. 
Table 1. Detailed items of the questionnaire

\begin{tabular}{|l|l|l|}
\hline & \multicolumn{1}{|c|}{ Questions } & Item Number \\
\hline Identifying code & The last four-digit number of the student's ID number & None \\
\hline Basic information & $\begin{array}{l}\text { Gender, age group, language proficiency (self-evaluation), } \\
\text { Korean learning period }\end{array}$ & $1,2,3,4$ \\
\hline \multirow{2}{*}{ Overall satisfaction } & $\begin{array}{l}\text { Please rate how well you liked the WeChat project this } \\
\text { semester }\end{array}$ & 5 \\
\hline $\begin{array}{l}\text { Degree of usefulness of } \\
\text { different components }\end{array}$ & Sharing lecture video clips & \multirow{2}{*}{$6,7,8,9,10$} \\
\cline { 2 - 2 } & Asking and answering questions & \\
\cline { 2 - 2 } & Performing simple writing tasks & \multirow{2}{*}{11,12} \\
\cline { 2 - 2 } $\begin{array}{l}\text { Willingness to use } \\
\text { WeChat }\end{array}$ & Socializing & $\begin{array}{l}\text { I hope the Korean language program will continue to use } \\
\text { the WeChat project in the future. }\end{array}$ \\
\cline { 2 - 3 } & $\begin{array}{l}\text { Sharing information related to lectures } \\
\text { interested in taking Korean. }\end{array}$ & \\
\hline
\end{tabular}

Next, 10 of the 17 students participated in the follow-up interview. Semi-structured interviews were conducted by freely listening to students' opinions and responses to questions that the instructor had prepared in advance. Two common questions included: 1) what do you think about the various components of WeChat that support Korean language learning this semester? (Please tell me in detail what you liked or disliked); and 2) what advantages and disadvantages do you think WeChat has in learning Korean? (Tell me about your experience). Each interview lasted for approximately 25 minutes.

The results of the questionnaire analysis are discussed in Research Question 1, and the interview data that were examined are detailed in Research Questions 2 and 3. The key research questions are as follows:

1. To what degree is using WeChat effective and helpful in learning Korean?

2. What are the advantages of using WeChat in learning Korean?

3. What are the disadvantages of using WeChat in learning Korean and what possible improvement can be made?

\section{$4 \quad$ Results analysis and discussion}

All 17 students who were enrolled in the KOR2003 course were invited to participate in this study, and data were collected by a purposive sampling technique. Two aspects of data analysis were undertaken. The first was a questionnaire. In total, 16 out of 17 questionnaires were valid and were used for the data analysis. All of the results for each question were explained descriptively. The second set of data came from interviews. In total, 10 out of 17 students voluntarily participated, and the interview data were analyzed in line with the grounded theory approach [18]. All interviews were audio-recorded and transcribed into Korean line-by-line by the author. The interviews were mostly conducted in Mandarin, but occasionally there was a mixture of Korean 
and English. As data analysis progressed, significant themes were identified repeatedly and incrementally.

\subsection{Research question 1: effectiveness}

Overall experiences. To understand how the students perceived their overall experience with the WeChat Project during this semester, they were asked to "please rate how well you liked the WeChat Project this semester." As shown in Table 2, the students generally felt positive and satisfied about using WeChat to learn Korean $(M=5.69$, $S D=1.04)$

Table 2. Overall experience with WeChat in Korean learning

\begin{tabular}{|l|c|c|c|c|}
\hline & Minimum & Maximum & Mean & Standard Deviation \\
\hline Overall experience & 4 & 7 & 5.69 & 1.04 \\
\hline
\end{tabular}

With a closer examination, 4 out of the 16 students selected point " 7 ," indicating that they were very satisfied with this WeChat Project. Further, 6 students provided "6," and " 5 " and " 4 " were provided by 3 students each. Considering that " 4 " was the median on the Likert scale for this question, it is probable that all students positively perceived the WeChat Project.

In the subjective question asking the reason for the ratings, students answered that they enjoyed this experience because "WeChat is a convenient platform," "it is easy to use," "it can get information quickly," and "it is convenient for communicating."

Usefulness of different components. In addition to their overall experience with the WeChat Project, students were asked to evaluate the degree of usefulness regarding the WeChat Project's five components and provide reasons. The components included sharing lecture video clips, asking and answering questions using new vocabulary and expressions, performing simple writing tasking using certain grammatical patterns or expressions, socializing, and sharing information related to lectures. The rating results for these components are listed in Table 3.

Table 3. Usefulness of WeChat project components

\begin{tabular}{|l|c|c|c|c|}
\hline & Minimum & Maximum & Mean & $\begin{array}{c}\text { Standard } \\
\text { Deviation }\end{array}$ \\
\hline Sharing lecture video clips & 4 & 7 & 5.63 & 0.86 \\
\hline $\begin{array}{l}\text { Asking and answering } \\
\text { questions }\end{array}$ & 3 & 7 & 5.94 & 1.20 \\
\hline $\begin{array}{l}\text { Performing simple writing } \\
\text { tasks }\end{array}$ & 4 & 7 & 6.25 & 0.90 \\
\hline Socializing & 3 & 7 & 6.06 & 1.20 \\
\hline $\begin{array}{l}\text { Sharing information related } \\
\text { to lectures }\end{array}$ & 5 & 7 & 6.50 & 0.61 \\
\hline
\end{tabular}

The results displayed in Table 2 reveal that the students generally acknowledged the usefulness of all five components of the WeChat Project. Of the five components, the 
students perceived that sharing information related to lectures was the most useful, followed by performing simple writing tasks, socializing, asking and answering questions, and sharing lecture video clips (which was considered the least helpful).

Students' feedback regarding the component of sharing information related to lectures was specific and positive - such as "I can get accurate information," "important information can be checked again at any time," it was "more convenient than e-mail," and it made students "well prepared for class." Subsequently, although the component of performing simple writing tasks was not ranked as the most useful, students mainly provided positive feedback such as "it is a fun and interesting way to practice Korean," "it is good to get used to the Korean keyboard," and "it is a good way to review what we learned."

The socializing component was evaluated as "interesting," and students mentioned that "the atmosphere of the class seems to be getting closer." However, some students mentioned that "it bothers me," and that it was a "little annoying."

The component of asking and answering questions received not only positive feedback - such as "it helps to review vocabularies learned in class" and "it seems to help both learning and socializing" — but also negative feedback — such as that students felt "burdened," and how one student felt "confused because I don't know what to do."

Finally, the component for sharing lecture video clips received only short and simple comments such as "good," "nice," and "helpful."

Intention to use and recommend. Finally, students were asked to rate how much they were willing to recommend the WeChat Project to other students as well as how much they wanted to continue using the WeChat Project in their Korean language course. As Table 4 shows, the students provided fairly high ratings for both statements.

Table 4. Intention to use and recommend the WeChat project

\begin{tabular}{|l|c|c|c|c|}
\hline & Minimum & Maximum & Mean & Standard Deviation \\
\hline Future use & 5 & 7 & 6.44 & 0.79 \\
\hline Recommendation & 5 & 7 & 6.25 & 0.75 \\
\hline
\end{tabular}

In examining the students' reasons, it was observed that students appreciated the WeChat Project because it was "interesting to use" and "easy and convenient." They also liked the project because "it was more convenient and helpful for learning Korean" and "it allows to efficiently manage the time to prepare for class."

\subsection{Research question 2: advantages}

The reasons listed in the students' questionnaire were relatively simple and short. To closely examine the students' feedback, follow-up interviews were conducted, and the interview data were analyzed. Four themes that related to advantages were derived from the interview data: increased learning time, acquisition of linguistic knowledge, the Korean language community, and the convenience of using the WeChat application.

The WeChat Project expanded Korean language classes beyond the classroom's physical space, especially regarding students' time spent learning Korean. According to the students' interviews, the WeChat Project "appears to be exposed to a 24-hour 
learning environment," "it required spending more time than regular classes," and "it was good to use spare time to learn Korean." As an example to further highlight this point, one student stated, "By the end of the semester, it became a habit to check the Korean class group chat often. While checking the group chat, I often reviewed the contents of the Korean class."

In addition to the increased learning time, the WeChat Project was perceived to have helped students improve their Korean language skills in various areas-including grammar, usage of expressions, and writing. According to their responses, students appeared to enjoy the opportunity to use new vocabulary or grammar: "I could learn it easily because I used it myself," "it was good to look at other students' use of Korean," "I was able to correct what I misunderstood," and "I think it most helped when she summarized the wrong or awkward usage of students." There was a specific example of the project helping a student with awkward usage. One student explained how she had been using the expression "I have a question" incorrectly as "I have a problem." However, she was able to correct this error by observing how another student in the group chat used the expression correctly. The considerable vocabulary of Korean is based on Chinese characters, but their usage differs between Korea and China; this results in many errors in Chinese learners of Korean. For example, in the case of the student mentioned above, the Chinese character 问题 is used to mean "question" in China but "problem" in Korea.

Several students expressed their satisfaction regarding how they could build and facilitate the Korean language community. Representative comments included "Through the WeChat group chat, I was able to communicate better with my classmates," "I think the atmosphere of the class has become softer," and "I liked that I could ask my friends or teachers right away and solve the problem." Students especially considered the bonding created by the WeChat group chat important, and they valued how the bonding was further strengthened by asking and answering each other's questions in Korean in their WeChat Moments.

Finally, the students appreciated the convenience of using the WeChat application, as demonstrated in the following comments: "The most convenient," "the best," and "it was good that there was no need to access e-mail or LMS [the learning management system] for checking the class content." One student added, "It reminds me of a to-do-list note that I used in middle and high school years but it was upgraded very conveniently."

\subsection{Research question 3: disadvantages and improvements}

Students who attended the follow-up interviews referred to a few of the project's shortcomings and offered various suggestions for improving the WeChat Project. Their main comments mostly related to the real experience they had while using WeChat for a semester, and some suggestions related to the limitations of the WeChat application itself.

The most common complaint about the WeChat Project was the heavy workload imposed on students' learning outside class; some students felt "burdened," they "could not enjoy learning Korean enough," and they sometimes "wanted to ignore all the tasks." 
Many students stated that "it was very stressful when it overlapped with other class assignments or exam schedules." In response, the students suggested solutions - which included selectively adjusting the number of tasks according to the academic schedule, and using the WeChat Project as an opportunity to obtain additional credits (rather than making it mandatory).

Another frequently mentioned difficulty was the various WeChat Project components. Students expressed how "it was challenging to keep in mind and do all the tasks," and "there were some things that did not help much." Further, students generally hoped that the WeChat Project could be more "systematic" and "predictable." A suggested solution involved the "choice and concentration of the WeChat tasks." Students stated that it would be more efficient for them to choose and concentrate on the type of task that they preferred. Students also proposed that they could participate in changing the tasks by setting weekly schedules or dedicated time for certain tasks.

The limitations of the WeChat application were another complaint raised by the students. Although students generally appreciated the convenience of WeChat, many still felt that "it was cumbersome to check the past news again," and that "it was hard to download the data again after a certain period of time." Therefore, the students suggested that it would be helpful to post news and important course-related materials on the LMS as well as on the WeChat group chat.

Further, some students suggested that a confirmation procedure (e.g., a mini-quiz) should be added to check that they watched the required videos, while others suggested that setting a certain time limit to perform the tasks would be more effective.

\section{Conclusions}

This study aimed to examine the effect of incorporating WeChat into KFL education. A MALL model using WeChat was implemented into the course syllabi of a liberal arts college in China, and an empirical study was conducted to demonstrate that the MALL model benefits Korean learning. The questionnaire results and interview data revealed the following findings:

1. The students who participated in this study's WeChat Project generally welcomed the use of various WeChat functions in their Korean learning; they also hoped that the instructor continues to apply WeChat to support their Korean learning in the future.

2. The students considered all five components of the WeChat Project generally useful. The students regarded sharing information related to lectures as the most helpful component, and sharing lecture video clips as the least helpful.

3. The analyzed interview data indicated that students believed that the WeChat Project helped them increase their time spent learning Korean, improved their Korean linguistic knowledge, and facilitated the Korean language learning community. Further, the students enjoyed the convenience of using the WeChat application. The students identified some of the project's shortcomings and provided constructive feedback for future improvement. 
This study has several limitations. First, the number of participants $(n=16)$ was small. Second, the participants were all in the same language level as the intermediate Korean language students. In the future, it would be worth investigating how WeChat can be incorporated into Korean language learning by increasing the number of participants and using different levels of students. Third, because of the exploratory nature of this study, all data provided were based on student feedback through questionnaires and interviews. Further studies should be conducted to more objectively examine the WeChat Project's usefulness and effectiveness. Finally, as noted by several students, the inadequate components of the WeChat Project should be supplemented to ensure that the project is systematically implemented in Korean language learning.

Despite these limitations, this study is significant because it examines the effects of MALL by WeChat, which has never been reported in KFL so far, and provides practical data for improving the Korean language learning environment abroad.

\section{Acknowledgment}

This research work is supported by the DHSS Staff Research Fund, BNU-HKBU United International College.

\section{$7 \quad$ References}

[1] Ding, X. (2016). The effect of WeChat-assisted problem-based learning on the critical thinking disposition of EFL learners. International Journal of Emerging Technologies in Learning, 11(12): 23-29. https://doi.org/10.3991/ijet.v11i12.5927

[2] Shang, W. (2016). Construction and application of WeChat learning platform in "Folk Literature" teaching. International Journal of Emerging Technologies in Learning, 11(5): 10-15. https://doi.org/10.3991/ijet.v11i05.5688

[3] Jin, W., Zhirui, D. (2017). Research on mobile learning model of college English based on WeChat platform. EURASIA Journal of Mathematics Science and Technology Education, 13(8): 5847-5853. https://doi.org/10.12973/eurasia.2017.01034a

[4] Duman, G., Orhon, G., Gedik, N. (2014). Research trends in mobile assisted languages learning from 2000 to 2012. ReCALL Journal, 27(2): 197-216. https://doi.org/10.1017/ $\underline{\mathrm{S} 0958344014000287}$

[5] Chinnery, G.M. (2006). Going to MALL: Mobile-assisted language learning. Language Learning and Technology, 1: 9-16. https://scholarspace.manoa.hawaii.edu/bitstream/10125/ 44040/10 01 emerging.pdf

[6] Metruk, R. (2019). The call of MALL: The use of smartphones in higher education: A literature review. Revista Dilemas Contemporáneos: Educación, Política y Valores, 6(3): 1-22. https://www.proquest.com/openview/08f8cedb19c2df051784db8d28818adc/1?pqorigsite $=$ gscholar \&cbl $=4400984$

[7] Metruk, R. (2020). Confronting the challenges of MALL: Distraction, cheating, and teacher readiness. International Journal of Emerging Technologies in Learning, 15(1): 4-13. https:// doi.org/10.3991/ijet.v15i02.11325

[8] Kukulska-Hulme, A., Shield, L. (2008). An overview of mobile-assisted language learning: From content delivery to supported collaboration and interaction. ReCALL, 20(3): 271-289. https://doi.org/10.1017/S0958344008000335 
[9] Miangah, T., Nezarat, A. (2012). Mobile-assisted language learning. International Journal of Distrusted and Parallel Systems, 3(1): 309-319. https://doi.org/10.5121/ijdps.2012.3126

[10] Lee, H. (2013). Conjoint analysis for mobile devices for ubiquitous learning in higher education: The Korean case. Turkish Online Journal of Educational Technology, 12(1): 45-51. https://eric.ed.gov/?id=EJ1008866

[11] Zaki, A.A., Yunus, M.M. (2015). Potential of mobile learning in teaching of ESL academic writing. English Language Teaching, 8(6): 11-19. https://doi.org/10.5539/elt.v8n6p11

[12] Burston, J. (2015). Twenty years of MALL project implementation: A meta-analysis of learning outcomes. ReCALL, 27(1): 4-20. https://doi.org/10.1017/S0958344014000159

[13] Kwon, J. (2012). The application of Facebook to Korean elementary class. Journal of Korean Language Education, 23(4): 1-29. https://doi.org/10.18209/iakle.2012.23.4.1

[14] Ahn, J., Shim, Y. (2018). Exploring the instructional use of Instagram for Korean language learning. Journal of Korean Language Education, 29(4): 65-92. https://doi.org/10.18209/ iakle.2018.29.4.65

[15] Han, H. (2018). Teaching and learning Korean language using MALL (mobile-assisted language learning) in KFL: A case in Hong Kong. Journal of Learner-Centered Curriculum and Instruction, 18(6): 519-535. https://doi.org/10.22251/jlcci.2018.18.6.519

[16] Kim, A. (2020). The effects of flipped learning on Korean language learners' academic performance. Journal of Korean Language Education, 31(3): 77-98.

[17] Shi, Z., Luo, G., He, L. (2017). Mobile-assisted language learning using WeChat instant messaging. International Journal of Emerging Technologies in Learning, 12(2): 16-26. https://doi.org/10.3991/ijet.v12i02.6681

[18] Strauss, A., Corbin, J. (1994). Grounded theory methodology: An overview. In N. K. Denzin \& Y. S. Lincoln (Eds.), Handbook of qualitative research (pp. 273-285). Sage Publications, Inc.

\section{Author}

Arum Kim is an assistant professor in the Centre of Foreign Language and Culture at BNU-HKBU United International College in China. Her research interests focus on second language learning, multimedia language learning, and the effect of students' individual differences on second language acquisition.

Article submitted 2021-05-16. Resubmitted 2021-08-30. Final acceptance 2021-09-15. Final version published as submitted by the authors. 